\title{
Improving Differentiated Learning Among Primary School Teachers; Enhancing the Acquisition of Phonological and Reading Comprehension Skills. The Case of Buea Sub-Division, Cameroon
}

\author{
Awah Julia Azah, Ph.D. \\ Department of Educational Psychology, \\ Faculty of Education, University of Buea, Cameroon \\ Research Consultant: Foundation of Scientific Research, Community Based \\ Rehabilitation and Advocacy on Inclusive Education" (FORCAIE-Cameroon) \\ juliaazah@gmail.com
}

\begin{abstract}
Majority of Cameroon primary school pupils face the problem of acquiring reading skills to the extent that they actually go through primary school and complete without learning how to read fluently and accurately with understanding this is a very serious problem which begins at the pre reading level and kindergartens and even continue to the higher level of education . in such a scenario pupils with reading problems are identified as being unable to make a difference between letters $d$ and $b, p$ and $d$ etc. A quasi experimental research design was used for this study. Both purposive and random sampling techniques were used for the study. Only pupils who fulfilled particular conditions peculiar for the study were allowed to participate. a pre-designed EpiData Version 3.1 (EpiData Association, Odense Denmark, 2008) database which had in-built consistency and validation checks was used to enter the data. Results indicates that, the average score in phonology in the experimental group at pre-test was 2.889 with median at 3.000, and increased to 3.556 at post-test and this improvement was significant (Wilcoxon Signed Ranks test: $P=0.043$ ). In the control group, at pre-test, the average score was 2.667 and increased to 3.000 at post-test though this was not significant (Wilcoxon Signed Ranks test: $P=0.180$ ). The average score in vocabulary in the experimental group at pre-test was 2.556 with median at 3.000, and increased to 3.444 at post-test and this improvement was significant (Wilcoxon Signed Ranks test: $P=0.007)$. In the control group, at pre-test, the average score was 1.667 and increased to 2.556 at post-test and this was significant (Wilcoxon Signed Ranks test: P=0.020), therefore implying that the change in the experimental group was more obvious than in the control group; the null hypothesis is then rejected. This problem gets worse as the children progress if not identified and remedied at the initial stage. This has been one of the main leading cause of school dropout and fallen standards of education as well poor performance in public examinations. However with the prevalent problem, teachers educational authorities and school administrators are searching for learning and teach techniques that could help attend to the individual needs of children with reading problems .differentiated instruction has been considered one of such methods according to research.
\end{abstract}

Keywords: Differentiated Learning, Acquisition of Phonological and Reading Comprehension Skills

\section{INTRODUCTION}

Generally a child who is unable to read words, paragraph, passage, or text fluently has phonological and decoding problems and as such cannot make meaning or comprehend what he or she is reading. So all the reading skills are directly link together and cannot be treated in isolation from each other therefore In creating the concept of differentiation, Tomlinson (1999) incorporated a wide range of recent research on how diverse students learn. The concept was primarily founded on Dr. Howard Gardner's concept of multiple intelligences, coupled with the more recent instructional suggestions emerging from the brain-compatible research literature (Gardner, 2006). With this emphasis on diverse learning styles as a backdrop, Tomlinson encouraged teachers to personalize the instructional activities in order to challenge students with a highly interactive, challenging, and interesting curriculum. Teachers were encouraged to consider students' unique learning styles and then differentiate the educational activities presented in the class to provide for those divergent learning 
styles. In particular, Tomlinson (1999) encouraged differentiation in three areas: 1. Content (what is learned) 2. Process (how the content is mastered by the student) 3. Product (how the learning is observed and evaluated Research within the field of differentiated instruction indicate a positive effect on reading problems. There is evidence that providing all students with the same reading instruction can be detrimental to student achievement. In classrooms comprised of students with varied reading levels where the teachers did not engage in differentiated instruction, student achievement for the average and low achieving students suffered; high achieving students made merely modest gains (McGill-Franzen, Zmach, Solic, \& Zeig, 2006; Schumm, Moody, \& Vaughn, 2000). Other studies support the notion that differentiation in instruction is needed to narrow the achievement gap found in today's schools (Allington, 2005; O'Connor, Bell, Harty, Larkin, Sackor, \& Zigmond, 2002). Since teachers in non-differentiated classrooms often focus on the average learners, students of high ability or low ability do not receive instruction to adequately improve their reading ability

\subsection{Background to the Study}

Historically, children with reading problems start manifesting signs reading problems as early as when they start developing delayed speech. in such a case the parent may be the first person in the child's life to recognize a reading problem. A parents observation is critical because some of the earliest signs that foreshadow a reading problem can be seen during preschool and kindergarten years .difficulty manipulating sounds in words is one of the hallmark characteristics of reading problem and can be seen at a young age a child may struggle with rhyming, games, or recognizing words that start with the same sound.

Also children who have repeated ear infections during their early years eventually have problems developing reading skills. Children who have articulation problems or are late to talk, as compared to peers, are not only screened during preschool years for speech and hearing difficulties but also for possible reading problems. Early signs of reading include the following as stated by hall (2009) detecting differences in speech sound sand performing tasks that require this skill such as: Pronouncing new words and remembering them, breaking words apart into sounds, blending words together, to make words and remembering sounds of letters. Children with weak phonological skill soften prefers to guess at unknown words while reading because he is not very good at figuring out the sounds or blending them together .being able to sound out unknown words is an important skill children need in order to read text beyond primary three. When a primary school child refuse to read when being ask to read is a warning sign that they may be experiencing difficulties. Such children often find reading a boring exercise as so they tend to avoid the practice. Generally by the middle of the primary one, children should be able to read at least one hundred common words. Without which watch for these warning signs: doesn't know the sounds associated with all of the letters, skips words in a sentence and doesn't stop to do self correction, can't remember to sound out that occur several times on the page. And frequently guess at unknown words rather than sounding them out. Also worth looking out for is the child's hand writing. By the end of kindergarten the child should be writing words that contain most of the consonants sounds in a word even though the vowels will often be missing

However it is important not to panic if these signs are being manifested in children. Each child is unique and may exhibit just some of the signs while others may exhibit al of the signs. Early intervention strategies like of differentiated instruction techniques like pre-assessment, precision teaching. Instructional scaffolding and flexible grouping can help improve the acquisition of reading skills. Differentiated, or responsive, instruction is not a new concept. The Concern for attending to the needs of particular students is captured in writings about teaching in ancient Greece and Egypt, in descriptions of life in the one-room schoolhouse and in every instance where instructional plans are adjusted to better meet the needs of an individual learner. The roots of differentiated instruction go all the way back to the days of the one-room schoolhouse, where one teacher had students of all ages in one classroom. As the educational system transitioned to grading schools, it was assumed that children of the same age learned similarly. However in 1912, achievement tests were introduced, and the scores revealed the gaps in student's abilities within grade levels.

The concept differentiated reading instruction was originally based on the need for teachers to differentiate reading instruction in a way that will meet the needs of diverse learners in the general education classroom (Tomlinson, 1999; 2003). Because children reading levels vary the type of 
reading instruction they need also varies This includes students with learning disabilities as well as a number of other mild and moderate disabilities, since students with mild and moderate disabilities are quite likely to be included in general education classes. Children with reading problems generally face problems with fluency, word decoding, phonetics, phonology, vocabulary fluency and comprehension skills. Children with poor fluency read words slowly, and in isolation and often without any reflection. They tend to focus more on how to say the words and less on what the words in the sentence or paragraph mean. They also omit difficult and unfamiliar words inversions are also not uncommon characteristics of children with reading problems. Vocabulary knowledge is also a critical issue. Children who develop reading problems have limited word knowledge or partial understanding of meaning of words. The more word volume children have the better their understanding. the more word children have at the partial and full knowledge level, the better their comprehension of text. Children whose vocabulary is not fully developed by primary three often develop reading problems latter in school. Meanwhile children with weak phonological skill skip and omit words and often read without understanding. As such comprehension is a very big problem for them.

The above issues demand a proper conceptualization of the variables of the study. Based on the earlier works of Tomlinson (1999) Differentiated Instruction (Independent Variable) can be seen in three areas: 1 Content (what is learned) 2. Process (how the content is mastered by the student) 3. Product (how the learning is observed and evaluated). In order to effectively measure content, process and product, instructional procedures such as pre-assessment, precision teaching, brain based learning; instructional scaffolding and flexible grouping were used as indicators of the study. Reading Problems (Dependent Variable) of the study was conceptualized based on the manifestation of difficulties in relation to phonological and phonemic awareness, word decoding, vocabulary, fluency and comprehension (Ehri, 2002).

Children with reading problems also have problems with spelling, while there are a number of rules, conventions and exceptions that take time to learn, spelling in the upper primary is only a concern if regular, phonetic words are misspelled. Spelling is a key decoding skill. A child may mistakenly spell the word /pull/ as /pool/which this researcher observed during the short evaluation exercise she had before establishing the basis for this study. Poor spelling is often an indication of poor phonics caused by weak phonological awareness. If phonetically spelled words are a problem, then children will have a hard time learning conventions and exceptions, as every word looks different. Many children with reading problems start to resist reading aloud in class or at home to their teacher and parents respectively and become easily distracted during reading periods in school and at home. Reading aloud is frustrating for struggling readers. They understand the pressure of teachers and parents, they see how easily their peers read and they feel frustration and shame that they cannot read. This is a major problem thus teachers are face with the challenge of making reading easy and more natural, so that young readers will become willing to acquire the skill. Comprehension (making meaning out of what is being read) is a major problem for children reading problems. Reading comprehension requires accuracy in decoding, so that the mind is completely available for comprehension, it requires interactive Meta cognitive reading approach, where a student is able to define main ideas and think critically about text. These skills do not develop in children with reading problems.

The other category of children with reading problems, like slow readers, those who don't enjoy reading, those who don't like reading and those who don't read for long periods of time may eventually learn the skill if identified and properly nurtured. Even though slow readers may not really perform as expected, this difficulty could impact homework efficiency and test taking, as well as may affect overall efficiency and performance. By identifying and treating the underlying difficulty, children with mild reading problems may eventually become fluent readers. Children with Reading problems have neurological disorders which cannot be treated but could be drilled to become knowledgeable. Children have reading problems because they lack specific skills necessary for proficient reading. When children have reading problems teachers need to identify where specific problems exist. Informal evaluation can be done in order to provide valuable information which can help determine possible gaps in necessary reading skills. After identification of missing reading skills a teacher is now expected to target instruction to directly help student in fundamental reading skills. The following reading skills must be evaluated, phonemic awareness, fluency performance in reading and spelling, decoding and comprehension. Children with reading problems are not receiving 
additional support in the context of the regular curriculum, not a different curriculum. The guiding principle here should be to provide all children with the same education, providing additional assistance and support as well as adapting teaching strategies to children requiring it as establish in the Salamanca statement and Framework for action 1994. The curricular content is too examination orientated and is not related to students learning experiences such that individual skills and abilities are not being exploited. The acquisition of knowledge is not only a matter of formal and theoretical instruction.

The worst case scenario is examination and assessment procedure. The examination and assessment procedure in our educational system are too rigid and less flexible. Although guidance materials and assistive devices exist, the Cameroon curriculum system does not make provision for this. For children with reading problems, a continuum of support is not provided ranging from minimal help in the regular classrooms to additional learning support programs and tools within the school and at home. This justifies why differentiated instruction is considered in classrooms of today for the teaching of children with reading problems. The 1995 National Forum on Education in Cameroon, revealed severe mediocrity in the educational output of primary school children. Consequently, it sought to give a new vision to the entire system of education. The determination of the government to redynamize the educational system became manifest in the promulgation on 14th April 1998, of the law on educational orientation. With the assistance of Projet d'Appui au Système Educatif Camerounais (PASECA), new teaching programmes have been introduced in Teacher Training Colleges (ENIEG), as well as Francophone and Anglophone primary schools conceived by the Inspector General for Pedagogy for Primary, Nursery and Teacher Education (IGP/PNTE). The 1998 Education law prescribed as a new mission/vision for Cameroonians schools, the training of children in view of their intellectual, physical, civic and moral welfare as well as their integration into the society taking into consideration the economic, socio-cultural, political and moral factors. Efforts and reflections in this direction led to the birth of a new pedagogic process- the New Pedagogic Approach (MINEDUC; NAP; 2002 p.4).

This approach is revealed as a powerful means of improving quality of the education and school output. The New Pedagogic Approach can be defined as a process, which places the child at the center of teaching/learning by appealing to his reasoning within the framework of classroom problemsolving situation. It is a method based on the development of inferential thinking. It recommends the use of teaching techniques that require exercises and thus, the development of thinking at all levels. These techniques enable the child to pass from simple identification exercises of memorization, recalling and /or application to a higher level of intellectual activity. In this manner he will acquire the ability to criticize, propose opinions, imagine, create and discover solutions to more or less complex problems. Such problems will normally require him to use his thinking, memory, understanding, application, analysis and evaluation system faculties (MINEDUC; ibid, p.11). This process, combined with compensatory education and competency-based approach, is believed will enhance efficiency in the educational system.

The institution and prescriptions of the new pedagogic approach falls in line with differentiated instruction which is of capital importance in the teaching of special needs students in general and children with reading problems in particular. The curriculum of general education in Cameroon at the primary school level is supposed to approach the individual learner as stated by Ronado (2009), which may be understood as a progressive opportunity to meeting the needs of individual learners. This approach provides an innovating way of conceiving and organizing the curricular structure and objective as well as the disciplinary content, in order to develop autonomous, critical and assertive citizens who can enjoy reading fluently. With the above in mind the big challenge is for teachers, curriculum planners and policy makers who are called upon to move away from rigid disciplinary content and toward a contextualize content as a significant resource for students.

\subsection{Statement of the Problem}

The goal of reading instruction is to help students learn how to create knowledge from what they read and apply it to specific problems in everyday life. Thus it is critical to success. But the actual problem that is prevalent in the educational sector nowadays in Cameroon is that there are many pupils that are unable to read fluently and accurately. Some even go through primary school and complete without acquiring reading skills to the extent that it affect academic life These problems are characterized by difficulties with decoding, fluency, phonology, word recognition, reading comprehension, inversion 
and omission of words. It is not as if children don't know sounds, many of them actually know the sounds but, cannot recognize them when trying to read out words. reading out words require being able to breakdown words into individual sounds for example turning the word cat into c/a/t, pat into $\mathrm{p} / \mathrm{a} / \mathrm{t}$. words beginning with $/ \mathrm{bl} /$ and $/ \mathrm{br} /, / \mathrm{ch} / \mathrm{and} / \mathrm{sh} /$ are even more challenging as well as similar sounding consonants like $/ \mathrm{mu} /$, and $/ \mathrm{nu} /$. They will also skip difficult words when reading. In such situations students prefer to read the words they recognize first and fill in the unknown words latter. Or if they cannot decode the word they will guess. Generally words are guessed or skipped because they are not recognized by the reader who is experiencing decoding problems.

\subsection{Purpose of Study}

The study was guided by two specific objectives, aimed at examining:

1) The effect of differentiated instruction on the performance of children in the acquisition of phonological skills.

2) The effect of differentiated instruction on the performance of children in the acquisition of reading comprehension. skills

\subsection{Research Questions}

The specific research questions included:

1) In what ways does differentiated instruction affect the performance of children in the acquisition of phonological skills?

2) To what extent does differentiated instruction affect the performance of children in the acquisition of reading comprehension?

\section{REVIEW OF LITERATURE}

\subsection{Conceptual Fame Work}

\subsubsection{Phonological and Phonemic Awareness}

In recent years, many researchers have explored the relationship between phonological awareness and success with reading and spelling. Phonological awareness is the area of oral language that relates to the ability to think about the sounds in a word (the word's phonological structure) rather than just the meaning of the word. It is an understanding of the structure of spoken language - that it is made up of words, and words consist of syllables, rhymes, and sounds. Fitzpatrick (1997) summarizes it best by saying that phonological awareness is "the ability to listen inside a word" (p5). Children who have well-developed phonological awareness when they come to school have a head start making sense of how sounds and letters operate in print. This ability is important for using sound-letter knowledge effectively in reading and writing. In fact, a student's level of phonological awareness at the end of kindergarten is one of the strongest predictors of future reading success, in grade one and beyond. Many children begin kindergarten with well-developed phonological awareness. Some seem to develop these skills fairly easily within a stimulating classroom environment, while others need more instruction that consciously and deliberately focuses on phonological awareness.

More than 20 percent of students struggle with some aspects of phonological awareness, while 8-10 percent exhibit significant delays. Early intervention is crucial and can make a real difference to students with limited levels of phonological awareness (Fitzpatrick, 1997) Students with a good understanding of phonological awareness have the underlying framework in place for reading (decoding) and writing (encoding) when letter-sound correspondences (phonics) are learned. Students who have difficulty with phonological awareness can often learn "phonics" (knowledge of letters and sounds), but they have difficulty using this knowledge as they read and spell. So, if students are expected to use letters and sounds as a source of information or cueing system as they read and spell (and they have to since English is based on an alphabetic system), it is important to ensure that all students have well-developed phonological awareness. Students who have difficulty with this area of language (approximately 20 percent) will struggle through school in figuring out how sounds work in print. They will not be able to use sound knowledge effectively because they will not have the underlying ability to "listen inside a word" and "play with the sounds" they hear (Fitzpatrick, 1997). 
Phonemic awareness is a component of phonological awareness involving the ability to hear, isolate and manipulate phonemes, for example the early reader must be able to hear the "at" sound in 'sat' and 'bat', and recognize that the difference between the words lies in the first sound. A child with phonemic awareness should also be able to manipulate this sound to form similar sounding or rhyming words e.g. cat, fat, mat (Hoover, 2002; Lyon, 2000; Westwood, 2008). Strong phonological and phonemic awareness and a good understanding of the alphabetic principle are fundamental skills for reading development and success (Wendling \& Mather, 2009). If a child cannot hear the phonemes in words they are unlikely to be able to manipulate them. Consequently they may struggle with learning how to relate the sounds they hear to the letters in written words (the alphabetic principle) and as a result will struggle to decode words efficiently and accurately (Westwood, 2001). A deficit in phonological awareness is believed to be the primary reason why many children have difficulty learning to read (Sharma et al., 2006; Blau et al., 2009; Ouimet \& Balaban, 2009; Rosen, 1999; Ahissar, et al., 2000).

\subsubsection{Comprehension}

Comprehension is the ultimate goal of reading. Everyone agrees that reading comprehension is not a simple matter of recognizing individual words, or even of understanding each individual word as our eyes pass over it. All models of comprehension recognize the need for readers to build up a mental representation of text, a process that requires integration across a range of sources of information, from lexical features through to knowledge concerning events in the world (Garnham, 2001; Gernsbacher, 1990; Kintsch, 1998). Given the complex nature of reading comprehension, it is not surprising that some individuals have difficulties in this area. Individual differences in text comprehension have been observed in both developmental (Nation \& Snowling, 1997; Oakhill, 1994) and college-aged populations (Gernsbacher \& Faust, 1991; Long, Seely, \& Oppy, 1999).

Reading comprehension is his construction of the meaning of a written or spoken communication through a reciprocal, holistic interchange of ideas between the interpreter and the message. The presumption here is that meaning resides in the intentional problem-solving, thinking processes of the interpreter. That the content of the meaning is influenced by that person's prior knowledge and experience. (Harris \& Hodges, 1995)

Noteworthy in this definition is the word construction. Reading comprehension is not simply the recall or regurgitation of information encountered in text. Reciprocal implies that that the reader brings something to reading comprehension-it's not just the information in the text; the information that the reader already possesses also influences the construction of meaning. And problem-solving, thinking processes suggest that the reader is actively involved in attempting to construct meaning. This also insinuates that the interpretation or understanding that a reader may construct may not be the same understanding constructed by another reader of the same text. Readers filter the text through their own background knowledge, biases, and other predispositions that affect how they interpret text.

\subsection{Traditional Methods of Teaching Reading}

\subsubsection{Directed or Guided Reading}

Guided reading requires children to read passages from books with some teacher assistance. This assistance is particularly important in interpreting the oral passages it is a useful strategy whenever it concerns a novice reader. Guided reading students need to apply reading strategies they have while reading text that are of an appropriate difficulty level for them. (Fountas and Pinnell,1996). Teachers work with four to six students who need similar types of reading instruction. teacher first introduce a text that students can read on their own with little support .teachers may provide a brief lesson that focuses on one or two strategies they want students to apply when reading teachers observe the students reading and provide additional assistance as needed. As students progress they read more difficult books and use the strategies. Guided reading lessons allow the teacher to model different types of questions those expert readers ask themselves while reading. Because asking questions about the text is key to understanding it we suggest developing guided reading lessons that demonstrate how to ask a variety of question type.

\subsection{Differentiated Instruction}

This section reviews literature in relation to the meaning, strategies and components of Differentiated Instruction. 


\subsubsection{Strategies for Differentiating Instruction}

Here we examine the strategies through which teachers can differentiate instruction in relation to the content, process, product and learning environment with the purpose of enhancing the learning experience. Five strategies are reviewed in this section. Namely, Pre-assessment, precision teaching, brain based learning, instructional scaffolding and flexible grouping.

\subsubsection{Pre-Assessment}

Pre-assessment plays a critical role in your ability to differentiate instruction. Teachers administer pre-assessments before instruction in a curricular unit in order to gain an understanding of what your students know, understand, and are able to do. Without pre-assessment, teachers do not know the preparedness of your students for new learning, the specific learning differences amongst students, or where to begin devising new curriculum goals (Heacox, 2009). It is a way to determine what students know about a topic before it is taught. It should be used regularly in all curricular areas

To make instructional decisions about student strengths and needs

To determine flexible grouping patterns

To determine which students are ready for advance instruction

According to Brighton (2009), present day public school classrooms are becoming increasingly diverse - students speak multiple languages, come from a variety of family configurations, represent a wide array of cultural groups and ethnic backgrounds, and have varied backgrounds and levels of academic readiness. How can a teacher possibly consider all of these students' prior experiences, preferred modes of learning, and tailor instructional levels to the appropriate degree of challenge? The answer to this complex question lies in a deceptively simple solution-systematically planning curriculum and instruction and constantly using data to drive this decision-making. In short, a teacher continually assesses the students (Brighton, 2009).

Pre-assessments can take a variety of formats and can range from completely separated from the instruction or can simultaneously serve as instruction and assessment. Depending on the purpose, a teacher can use a pre-assessment to;

1) Elicit information about students' readiness to learn skills and concepts;

2) Gather information about students' preferred modes of learning (including learning styles and grouping preferences); and

3) Gather information about students' attitudes about the learning, areas of interest within the study, and initial questions about the learning.

The most common form of pre-assessment is a pencil and paper test or quiz such as an "end of chapter" or "end of unit" test administered at the beginning of the instructional sequence. The primary purpose of this type of instrument is to gather information about a student's readiness to learn the concepts/skills and to determine what skills and understandings a student has prior to the start of the learning experience. In this situation, the teacher does not grade the pre-test, but instead uses the information to determine grouping of students and to determine whether some students require teaching of prerequisite skills or need additional degrees of challenge (Brighton, 2009).

An important part of differentiated instruction and assessment is determining what students already know so as not to cover material students have mastered, or use methods that would be ineffective for students. The goal of pre-assessment is to determine a student's knowledge, understanding and skill prior to the unit of study. These assessments are referred to as assessments for learning, which include diagnostic or pre- assessments to be used by the teacher to help guide their instruction and benefit each learner. They are informal and provide qualitative feedback to teachers and students to address strengths and needs during the unit. Pre-assessments should be conducted several weeks before the unit of study and should not be graded. Chapman and King (2005), note that when "teachers strategically administer pre-assessments - before planning their lessons, they can address the students' strengths and needs during instruction." Pre-assessment can be conducted in two ways: 1) by identifying learning preferences and interests (i.e. Gardner's Multiple Intelligence test, or Visual, Auditory, or Kinesthetic learner), and 2) by identifying knowledge of student understandings (i.e. 
checklists, quizzes, class discussion, portfolios, entry/exit cards, anticipation guides, journals, and self-reflections). Both of these types of pre-assessment are used to design Student tasks, particularly when a student might require support, enrichment, or have different learning styles, intelligences, or interests. Teachers can also determine, locate, and compile appropriate resources and decide time lines/priorities for upcoming units.

The goals of differentiated instruction are to develop engaging tasks that challenge and enhance learning for each student. Instructional activities are flexible, and based and evaluated on content, process, product, and learning environment. This instructional approach and choice of content are driven by the data from students' assessment results and from the outcomes of other screening tools. Pre-assessments can gather information about each student's strengths, comforts, or areas of weakness. This leads to appropriate differentiation that accommodates each student's learning needs and preferences. Assessments should be used as a tool to create clear and meaningful instruction that guide each student towards challenging but not frustrating activities.

\subsubsection{Precision Teaching}

Precision Teaching is a method developed in the 1960s, at Harvard University, by Ogden Lindsey (Lindsley, 1990). It grew out of the tradition of behaviorism and direct instructions and was first tested in a Montessori class for children with learning difficulties. It is also called 'Fluency Learning' and has been used successfully with university graduates, as well as students with diverse problems such as autism, attention deficit or severe intellectual disabilities (White, 1986). Lindsley emphasized the evaluation and revision components of systematic instruction by encouraging teachers and students to pinpoint behaviors, count, time and chart them every day, and "try, try again" when initial procedures did not produce the desired results (Lindsley, 1972). Lindsley (1964) wrote: "Children are not retarded. Only their behavior in average environments is sometimes retarded. In fact, it is modern science's ability to design suitable environments for these children who are retarded" (p. 62). A key element of Precision Teaching is the dictum that "the child knows best" (Lindsley, 1972). Based on Skinner's famous statement that "the organism is always right," Lindsley taught Precision Teachers to assume that learners respond in lawful ways to environmental variables and that if learners behave in an undesirable way it is the responsibility of teachers to alter those variables until they produce the desired result. This assumption, perhaps obvious to most current-day performance technologists flies in the face of traditional psycho-educational practice which tends to label and to blame students for failure, not instructional methods.

\subsubsection{Brain Based Learning (BBL)}

Howard Gardner's seminal book Frames of Mind: The Theory of Multiple Intelligences (1983) taught educators around the globe to understand the actual connections that the brain has with learning. Beginning in the late 1980s and the early 1990s, thousands of American teachers became intensely interested in learning about the brain-based multiple intelligences and finding multiple ways to reach their increasing numbers of diverse learners. Brain-Based Learning can be viewed as techniques gleaned from research in neurology and cognitive science used to enhance teacher instruction. These strategies can also be used to enhance students' ability to learn using ways in which they feel most comfortable, neurologically speaking. Jensen (1995/2000) defines BBL as "learning in accordance with the way the brain is naturally designed to learn" (p .6). Perhaps the most important aspect of BBL is that it encompasses and combines specific types of research-based academic interventions as well as applied aspects of emotional learning. A basic component of brain-based learning is that our emotions influence our ability to learn. Our brains are constantly striving to make connections between intellect and emotions. Jensen (1995/2000) explains that the "brain attaches emotion to each event and thought, forming patterns of meaning ..." (p. 9). Generally speaking, teachers have paid little attention to the emotional content of lessons. Chapman and King (2003) quote Robert Sylwester as explaining in an interview with Marcia d'Arcangelo: "[o]ur emotional system drives our attentional system, which drives learning and memory and everything else that we do. It is biologically impossible to learn and remember anything to which we don't pay attention" (p. 141). The emotional system tells us whether something is important - whether we ought to put energy or effort into it. In other words, teachers are most likely to gain, and keep, the attention of students when they engage student brain-based emotional systems in a challenging yet non-intrusive manner. 


\subsubsection{Instructional Scaffolding}

Researchers have invoked the notion of scaffolding, a construct originally crafted to characterize how more experienced peers or adults can assist learners. As defined and used in early research, scaffolding is said to occur when a more knowledgeable person helps a learner succeed in tasks that would be other wise beyond their reach (Wood, Bruner, \&Ross, 1976). In the last two decades of learning sciences research, scaffolding has become increasingly prominent. Scaffolding is a key strategy in cognitive apprenticeship, in which students can learn by taking increasing responsibility and ownership for their role in complex problem solving with the structure and guidance of more knowledgeable mentors or teachers (Collins, Brown, \& Newman, 1989). Many different approaches to scaffolding have emerged from the design research on interactive learning environments, and a variety of design guidelines or principles have been proposed (Edelson et al., 1999; Guzdial, 1994; Kolodner, Owensby, \& Guzdial, 2004; Linn, 2000; Reiser et al., 2001). To engage in principled development and empirical study of design guidelines requires greater clarity concerning what is meant when one says that a tool has scaffold learners, and requires a model of how the tool has benefited learners. In particular, it is important to characterize the mechanisms by which a software tool can provide scaffolding for learners. Developing a common system of design guidelines for scaffold software requires such a model of mechanisms that explain why a tool reflecting these guidelines would benefit learners.

The conception is associated with Vygotsky's (1978) notion of the zone of proximal development, which characterizes the region of tasks between what the learner could accomplish alone and what he or she could accomplish (and master) with assistance (Rogoff, 1990). The idea of scaffolding is now in increasing use in educational design. In these contexts, the intention is that the support not only assists learners in accomplishing tasks but also enables them to learn from the experience. The use of the notion of scaffolding has not always been explicitly limited to learning settings. For example, one might consider an adult providing support to a child for some task (such as observing an animal at the zoo) in which there is no intention that the child learns to perform the task in the future more effectively. For educational settings, it is important to stress the dual aspects of both (a) accomplishing the task and (b) learning from one's efforts, that is, improving one's performance on the future tasks in the process. If learners are assisted in the task but are not able to understand or take advantage of the experience, the assistance will have been local to that instance of scaffolding but will not have provided support for learning. Thus, scaffolding entails a delicate negotiation between providing support and continuing to engage learners actively in the process (Hogan, Nastasi, \& Pressley, 1999; Merrill, Reiser, Merrill, \& Landes, 1995). Lepper, Woolverton, Mumme, and Gurtner (1993) described this as maintaining an "optimum" level of challenge for learners. I return to the need for balancing assistance with ensuring the work on the task is productive in later discussions of the two scaffolding mechanisms.

\subsubsection{Components of Differentiated Instruction}

According to Tomlinson (2005), teachers can differentiate instruction through four ways: 1) Content, 2) Process, 3) Product, and 4) learning environment in relationship to interest readiness and learning profile/preference.

\subsubsection{Content}

The content of lessons may be differentiated based on what students already know. The most basic content of a lesson should cover the standards of learning set by the ministry of education. Some students in a class may be completely unfamiliar with the concepts in a lesson, some students may have partial mastery of the content-or display mistaken ideas about the content, and some students may show mastery of the content before the lesson begins. The teacher may differentiate the content by designing activities for groups of students that cover different areas of Bloom's Taxonomy. For example, students who are unfamiliar with the concepts may be required to complete tasks on the lower levels of Bloom's Taxonomy: knowledge, comprehension, and application. Students who have high levels of mastery may be asked to complete tasks in evaluation and synthesis. When teachers differentiate content, they may adapt what they want the students to learn or how the students will gain access to the knowledge, understanding, and skills (Anderson, 2007). In these instances, educators are not varying student objectives or lowering performance standards for students. They 
different texts, novels, or short stories at a reading level appropriate for each individual student. Teachers can use flexible groups and have students assigned to groups like listening to audio books or accessing specific internet sources. Students could have choice to work in pairs, groups, or individually, but all students are working towards the same standards and objectives.

Examples of differentiating reading activities:

Match vocabulary words to definitions

Read a passage of text and answer related questions

Think of a situation that happened to a character in the story and a different outcome.

Differentiate fact from opinion in the story.

Identify an author's position and provide evidence to support this viewpoint.

Create a PowerPoint presentation summarizing the lesson.

Using reading materials at varying readability levels;

Putting text materials on tape;

Using spelling or vocabulary lists at readiness levels of students;

Presenting ideas through both auditory and visual means, and

Meeting with small groups to re-teach an idea or skill for struggling readers, or to extend the thinking or skills of advanced learners.

\subsubsection{Product}

The product is essentially what the student produces at the end of the lesson to demonstrate the mastery of the content through tests, evaluations, projects, reports, or other activities. Based on students' skill levels and educational standards, teachers may assign students to complete activities that demonstrate mastery of an educational concept (writing a report), or in a method the student prefers (composing an original song about the content, or building a three dimensional object that explains mastery of concepts in the lesson or unit). The primarily determine both the 'what' and 'how' instruction will be delivered. When an educator differentiates by product or performance, they are affording students various ways of demonstrating what they have learned from the lesson or unit; (Nunley, 2006). It is done by using menu unit sheets, choice boards or open-ended lists of final product options. It is meant to allow students to show what they learned based on their learning preferences, interests and strengths.

Examples of differentiated structures include Layered Curriculum, tiered instructional tic-tac-toe extension menus, Curry/Samara models, RAFT writing activities, and similar designs.

In differentiated instruction, teachers respond to students' readiness, instructional needs, interests and learning preferences and provide opportunities for students to work in varied instructional formats. A classroom that utilizes differentiated instruction is a learner-responsive, teacher- facilitated classroom where all students have the opportunity to meet curriculum foundation objectives. Lessons may be on inquiry based, problem based and project based instruction. The product is what the student creates at the end of the lesson to demonstrate the mastery of the content. This can be in the form of tests, projects, reports or other activities. Teachers may assign students to complete activities that show mastery of an educational concept in a way the student prefers, based on learning styles.

Examples of differentiating the end product:

Read and write learners write a book report.

Visual learners create a graphic organizer of the story.

Auditory learners give an oral report

Kinesthetic learners build a diorama illustrating the story.

Giving students options of how to express required learning (e.g., create a puppet show, write a letter, or develop a mural with labels); 
Using rubrics that match and extend students' varied skills levels;

Allowing students to work alone or in small groups on their products; and

Encouraging students to create their own product assignments as long as these assignments contain required elements.

\subsection{Theoretical Framework}

The rational to consider a new model of learning and teaching reading is directed by current student diversity, brain research, but also theories. Theories about how students learn, the content they learn and instructional strategies used by the teacher. Individuals do not learn in the same way, consequently, contemporary education has been influenced by several renowned theorist who have investigated the different methods learners use to conceptualize ideas. Theories that have helped in strengthening knowledge in the educational field, and have assisted educators to examine instructional practices, changing curriculum and assessment technique. Thus the theoretical framework of this study will focus on Social Constructivism, the theory of Need Based Assessment, Bruner's Modes of Representation and the Theory of Multiple Intelligences.

\subsubsection{Bruner's Modes of Representation (1915)}

In his book the Process of Education, Bruner (1978) argued that students should be helped to understand the structure of a field of study or the discipline. Bruner believed that if students are helped to grasp the overall pattern of a field of study, they are more likely to remember what they learn, and understand the principles that can be applied in a variety of situations (Tchombe, 2011). He insisted on discovery learning in his book "Beyond the Information Given" (Bruner, 1980) which must guide teaching in classrooms, where school learning takes too much the form of step by step presentation of knowledge which are applicable only in the classroom. His concern for structure ties with the views of the Gestalt psychologists. Bruner's theory presents three modes of representation: enactive (based on physical actions and experiences), iconic (use of mental images based on visual, auditory, olfactory or tactile senses), and symbolic (use of language, number, music, etc). Bruner's theory demonstrates a degree of transitions from enactive, iconic and symbolic modes of representations that impacts learning. Bruner's theory addresses learning process based on his mental bridge being the role of perception in cognitive learning (Tchombe, 2011). Perception is an interpretative mechanism that enables the establishment of meaning through sensory stimulations. Traditional sensory stimulation theory has as its basic premise that effective learning occurs when the senses are stimulated (Laird, 1985). Teachers have to learn to stimulate the senses because the bulk of learning is through the senses: seeing, hearing, touching, smelling and tasting. By stimulating the senses, especially the visual and auditory senses, learning is enhanced. Learning is perceived as a cognitive process involving the acquisition and transformation of knowledge and its potentials for responding to new situations. Bruner's theory advocates discovery learning (Bruner, 1961). Bruner insists on intrinsic motivation to move towards higher order learning with focus on diversity of learning.

\subsubsection{Relevance of Bruner's Theory}

This theory is of relevance to differentiated instruction especially at the iconic and symbolic modes of representation that has to do with reading problems. Teachers have a lot to learn from Bruner's theory regarding Instructional differentiation. According to Tchombe (2011), teachers should confront students with problem and help them look for solutions either independently or in interactive group work. This approach highlights the importance of student-directed learning. Teachers should give students much opportunity for practice so that they can acquire confidence in their own learning abilities. Students should be given the opportunity to make individual or small group discoveries in form of projects or term papers (Tchombe, 2011)

\subsubsection{Gardner's Theory of Multiple Intelligences (1991)}

Howard Gardner of Harvard has identified seven distinct intelligences. This theory has emerged from recent cognitive research and "documents the extent to which students possess different kinds of minds and therefore learn, remember, perform, and understand in different ways," according to Gardner (1991). According to this theory, we are all able to know the world through language, 
logical-mathematical analysis, spatial representation, musical thinking, and the use of the body to solve problems or to make things, an understanding of other individuals, and an understanding of ourselves. Where individuals differ is in the strength of these intelligences - the so-called profile of intelligences -and in the ways in which such intelligences are invoked and combined to carry out different tasks, solve diverse problems, and progress in various domains.

Gardner says that these differences challenge an educational system that assumes that everyone can learn the same materials in the same way and that a uniform, universal measure suffices to test student learning. Indeed, as currently constituted, our educational system is heavily biased toward linguistic modes of instruction and assessment and, to a somewhat lesser degree, toward logical-quantitative modes as well. Gardner argues that a contrasting set of assumptions is more likely to be educationally effective. Students learn in ways that are identifiably distinctive. The broad spectrum of students - and perhaps the society as a whole - would be better served if disciplines could be presented in a numbers of ways and learning could be accessed through a variety of means. The intelligences are as follows:

Visual-Spatial - Think in terms of physical space, as architects and sailors. Very aware of their environments. They like to draw, do jigsaw puzzles, read maps, and daydream. They can be taught through drawings, verbal and physical imagery. Tools include models, graphics, charts, photographs, drawings, 3-D modeling, video, videoconferencing, television, multimedia, texts with pictures/charts/graphs.

Bodily-kinesthetic - Use the body effectively, like a dancer or a surgeons keen sense of body awareness. They like movement, making things, touching. They communicate well through body language and can be taught through physical activity, hands-on learning, and acting out, role playing. Tools include equipment and real objects.

Musical - Shows sensitivity to rhythm and sound. They love music, but they are also sensitive to sounds in their environments. They may study better with music in the background. They can be taught by turning lessons into lyrics, speaking rhythmically, tapping out time. Tools include musical instruments, music, radio, stereo, CD-ROM, multimedia.

Interpersonal - Understanding, interacting with others. These students learn through interaction. They have many friends, empathy for others, street smarts. They can be taught through group activities, seminars, and dialogues. Tools include the telephone, audio conferencing, time and attention from the instructor, video conferencing, writing, computer conferencing, E-mail.

Intrapersonal - Understanding one's own interests, goals. These learners tend to shy away from others. They're in tune with their inner feelings; they have wisdom, intuition and motivation, as well as a strong will, confidence and opinions. They can be taught through independent study and introspection. Tools include books, creative materials, diaries, privacy and time. They are the most independent of the learners.

Linguistic - Using words effectively. These learners have highly developed auditory skills and often think in words. They like reading, playing word games, making up poetry or stories. They can be taught by encouraging them to say and see words, read books together. Tools include computers, games, multimedia, books, tape recorders, and lecture.

Logical - Mathematical - Reasoning, calculating. Think conceptually, abstractly and are able to see and explore patterns and relationships. They like to experiment, solve puzzles, and ask cosmic questions. They can be taught through logic games, investigations, and mysteries. They need to learn and form concepts before they can deal with.

\subsubsection{Relevance of Gardner's Theory}

Gardner's theory of the multiple intelligences is a departure from the view that intelligence is a single, measurable unit (Gardner, 1999). Gardner's theory focuses on eight intelligences, while highlighting the need for problem-solving (Campbell, Campbell, and Dickinson, 1999). An instructional technique or program that is heavily reliant on one of the intelligences, minimizes opportunities for students who may not possess a propensity to learn in this way (Gardner, 1999).These students, who may not achieve in the traditional way, may become lost to both the school and the community at large (Campbell et al., 1999; Gardner, 1999). The multiple intelligences are presented as tools for learning and problem solving (Campbell et al., 1999; Green, 1999). Creating opportunities for all students, by enriching the classroom through multiple techniques and assessment forms, develops students and brings out their strengths (Campbell et al., 1999; Gardner, 1999; Green, 1999). 


\section{RESEARCH DESIGN}

A quasi experimental research design was used for this study. The purpose of the quasi experimental design was to determine the cause and effect relationship that exist between differentiated instruction and reading problem according to Campbell (2008), this design differs in the pure experimental study in that it lacks the elements of random assignments to treatment and control groups. This was done by exposing one of the groups to a treatment of differentiated instruction. In such a research design, there was a parallel group design, that is, two groups were studied, the control and experimental groups. The control group is the group to which no special treatment is administered while the experimental group is that which the special treatment was being administered. There were two variables, differentiated instruction which is the main independent variable or treatment variable while the dependent or observed performance of children with reading problems is the dependent variable. The experimental group of students was thought using differentiated instructional strategies, while the control group was taught using traditional methods of teaching.Sub-treatment variables or indicators for the various hypotheses were

1) The effect of differentiated instruction on phonology skills.

2) The effect of differentiated instruction on vocabulary skills

There researcher made use of pre-test and post-test techniques in the administration the instruments. This implies that students of the control group were taught using traditional methods while differentiated method of instruction was used for teaching students of the experimental group. After the exercise which lasted for six weeks a post test was given in order to assess the validity of the differentiated method of teaching as a holistic approach to teaching children with reading problems. Besides the above quantitative method, the researcher made use of other qualitative methods of data collection, such as observations and interviews in order to have more data to support the results of the study.

\subsection{Population of the Study}

The population of this study consisted of all the primary school pupils and teachers in Buea subdivision this is elaborated in the table that follows.

Table2. Population of The Study

\begin{tabular}{|l|c|c|c|}
\hline \multicolumn{1}{c|}{ Category of School } & \multirow{2}{*}{$\begin{array}{c}\text { Number of } \\
\text { Schools }\end{array}$} & Teacher & Pupils \\
\cline { 3 - 4 } & 34 & 384 & 8,349 \\
\hline Public & 18 & 106 & 2,266 \\
\hline Confessional & 43 & 223 & 3,106 \\
\hline Lay Private & 95 & 713 & 13,721 \\
\hline Total & &
\end{tabular}

Thus the population of this study was 13,721 which was further classified into target and accessible population

Table3. Summary Of Target Population

\begin{tabular}{|l|c|c|c|}
\hline \multicolumn{1}{|c|}{ Category of School } & $\begin{array}{c}\text { Population of the } \\
\text { Study }\end{array}$ & Teacher & Pupils \\
\cline { 3 - 4 } & 8,349 & 384 & 1,311 \\
\hline Public & 2,266 & 106 & 401 \\
\hline Confessional & 3,106 & 223 & 566 \\
\hline Lay Private & 13,721 & 713 & 2,278 \\
\hline Total &
\end{tabular}

This implies that the target population was 713 teachers and 2278 pupils.

\subsection{Accessible Population}

According to Nworgu (2004), the accessible population that is within the reach of the researcher. Explorable.com (2004) also sees the accessible population as a subset of the target population the researcher at times draws his sample from the accessible population or could use it as its sample particularly when its number is small and all could be used in the experiment or investigation. In this study, all the class four pupils of Government school Bukwai that is group one and group two constituted the accessible population which was used as the sample of the study. 
Table4. Accessible population was composed of primary four pupils of this school, with a total number of 22 pupils

\begin{tabular}{|c|c|c|}
\hline School & Class & Accessible Population or Sample for Pupils \\
\hline \multirow{2}{*}{ G.S Bokwai } & 2 & 22 \\
\cline { 2 - 3 } & & 22 \\
\hline \multicolumn{2}{|c|}{ Total } & \\
\hline
\end{tabular}

\subsection{Sample and Sampling Technique}

Both purposive and random sampling techniques were used for the study. Only pupils who fulfilled particular conditions peculiar for the study were allowed to participate. The sampling procedure went through two successive stages. First a pre-assessment reading test was given to primary four pupils. This test enabled the researcher to select children with reading problems that eventually participated in the study. Out of the twenty two pupils eighteen were identified with reading problems. These eighteen constituted the sample that participated in the study. Secondly, the children with reading problems were then randomly selected for the control and experimental groups. This was done by the use of lots. That is, nine papers were sealed with CG (control group) and nine others were sealed with EG (experimental group). The pupils were then made to pick up any of the papers. Any pupil, who picked up CG, belonged to the control and any pupil who picked EG belonged to the experimental group.

Table5. Population and Sample of the Study

\begin{tabular}{|c|c|c|c|}
\hline Total Population & Sample & Experimental Group & Control Group \\
\hline 19 & 14 & 7 & 7 \\
\hline
\end{tabular}

\section{INSTRUMENTATION}

The study made use of both quantitative and qualitative methods of data collection. Five instruments of data collection were used for the study.

1) Pre-assessment Test: This test was made of items in relation to phonological awareness, word decoding, vocabulary, fluency and comprehension. The purpose of this test was to identify learners with reading problems, who formed participants of the study.

2) Pre-Test: : A pre-test was administered at the start of each experiment since there were five experiments, each with a different objective five pre-test were designed and administered .This test composed of items relating to reading skills, such as, phonological awareness, word decoding, vocabulary, fluency and comprehension. The purpose of the pretest was to determine the initial performance of children with reading problems. This test was administered under the same conditions to both the control and experimental groups of the study.

3) Post-Test. After teaching the control and experimental groups within a period of six weeks a post test was administered. This test composed of items in relation to reading skills, such as, phonological awareness, word decoding, vocabulary, fluency and comprehension. The test was aimed at assessing the performance of the experimental and control groups after six weeks of exposure to different methods of instructions.

4) Interview Guide: A structured interview guide made of seven items was administered to teachers to solicit qualitative information from teachers on their knowledge and implementation of differentiated instructional methods in the classroom.

5) Classroom Observational Guide: This observational guide was equally aimed at observing the classroom interaction between teachers and pupils to see the extent to which differentiated instruction is used in the classroom.

\subsection{Treatment of Experimental and Control Groups}

In order to avoid the teacher variable affecting the results, the researcher personally taught the experimental and control groups during each experiment. In the first experiment the experimental group was taught reading skills using the differentiated teaching strategy of brain based learning while the control group was taught reading skills using the traditional textbook method. Each lesson lasted for thirty minutes within a period of one week. At the end of the end a post test was administered. In 
the second experiment the experimental group was taught reading skills using the differentiated teaching strategy of instructional scaffolding while the control group was taught reading skills using the traditional text book method. Each lesson lasted for thirty minutes within a period of one week. At the end of the end a post test was administered.

\subsection{Quantitative Data Analysis}

As for the quantitative data, a pre-designed EpiData Version 3.1 (EpiData Association, Odense Denmark, 2008) database which had in-built consistency and validation checks was used to enter the data. Further consistency, data range and validation checks were also performed in SPSS version 21.0 (IBM Inc., 2012) to identify invalid codes. Data were made essentially of categorical variables hence; chi-Square test of independence was used to measure the cause and effect relationship between the conceptual indicators of the study. The Explanatory Power (EP) of individual background indicators like gender, age was calculated as well as the Integrated Value Mapping (IVM) using Cox and Snell Pseudo R-Square. The effect of these indicators was also appraised using the Log-Likelihood Ratio test. The P-Value could tell us if the effect was significant or not. In fact, the smaller the P-value, the more the contribution and which contribution is significant when P-value is $<0.05$. Inter-component relationship or association between the indicators of differentiated instruction was assessed using the non-parametric Spearman's rho correlation test. The non-parametric correlation test was used because composite variables departed significantly from theoretical normal distribution according to Kolmogorov Smirnov and Shapiro Wilk test $(\mathrm{P}<0.05)$ All statistics were presented at the 95\% Confidence Level (CL), Alpha $=0.05$. In the other sense, whenever the P-value was less than Alpha, there was significant difference, a significant relationship, a significant dependence or association or a significant variability explained.

The following statistical Measures were used in quantitative data analysis.

a) Chi-Square: The use of Chi square demands that data should be categorical and variables made of two or more categories. (Greenwood \& Nikulin, 1996). The use of Chi-square was meant to measure the effect of differentiated instruction on the performance of children with reading problems. The Chi-Square was the most suitable for this purpose because data were made essentially of categorical variables.

b) Log-Likelihood Ratio Test (Pseudo R-Square): Logistic regression, also called a logit model, is used to model dichotomous outcome variables. In the logit model the log odds of the outcome is modelled as a linear combination of the predictor variables (Hosmer \& Lemeshow, 2000). The likelihood ratio test was meant to determine the predictive value of gender and age on performance in reading problems. This was the most efficient test that could indicate the predictive value of individual categorical and dichotomous variables that were not continues.

The Log-Likelihood Ratio Test was equally used to determine which of the differentiated instructional strategies had the highest predictive value on the performance pupils with reading problems.

\subsection{Quantitative data was represented using tables and charts}

\subsubsection{Qualitative Data Analysis}

The analysis of data (interviews and observations) was done following the systematic process of thematic and content analysis (Ellen \& Renner, 2003). The first stage involved making a decision on the level of analysis. At this level, single words, clauses and sets of words or phrases were coded. A decision was made on how many different concepts to code. This involved developing pre-defined or interactive sets of concepts categories. A code list earlier developed based on the major indicators of the study was made. The primary documents of textual data were coded for existence and for frequency of concepts by coding for every single positive or negative word or phrase that appeared. Relevant categories not included in the initial code list were added during the coding process (in vivo coding). Introducing this coding flexibility allowed for new, important material to be incorporated into the coding process that could have significant bearings on results. During the coding it was assumed that any idea that emerges at least once is relevant. The ideas are therefore considered more important than frequency. However, the frequency also reflects how many times a concept emerges and is a major indicator of emphasis. Ideas were coded relating to a concept in comments discriminatively for neutral, positive, or negative sense. After taking the generalization of concepts into consideration, translation rules were created that allowed the streamlining and organization of the 
coding process so that what was being coded for is what was intended to be coded. This stage enabled me to determine the meaning of words and what they stand for so as to know where to code each statement.

\section{SUMMARY OF FindingS}

Research hypothesis one: Differentiated instruction has no significant effect on the performance of children problems acquiring phonological skills.

Table: Comparing phonology scores within group from pre-test to prost-test and between experimental and control group.

\begin{tabular}{|c|c|c|c|c|c|}
\hline \multicolumn{2}{|c|}{ Group } & Phonology pre-test & Phonology post test & $\begin{array}{c}\text { Mean } \\
\text { difference }\end{array}$ & $\begin{array}{l}\text { Wilcoxon Signed } \\
\text { Ranks test }\end{array}$ \\
\hline \multirow[t]{6}{*}{ Experimental } & $\mathrm{N}$ & 9 & 9 & \multirow{6}{*}{0.667} & \multirow{6}{*}{$\begin{array}{c}Z=-1.730 \\
P=0.043\end{array}$} \\
\hline & Mean & 2.889 & 3.556 & & \\
\hline & Median & 3.000 & 4.000 & & \\
\hline & Minimum & 2.00 & 3.00 & & \\
\hline & Maximum & 4.00 & 4.00 & & \\
\hline & Std. Deviation & 0.601 & 0.527 & & \\
\hline \multirow[t]{6}{*}{ Control } & $\mathrm{N}$ & 9 & 9 & \multirow{6}{*}{0.333} & \multirow{6}{*}{$\begin{aligned} Z & =-1.342 \\
P & =0.180\end{aligned}$} \\
\hline & Mean & 2.667 & 3.000 & & \\
\hline & Median & 3.000 & 3.000 & & \\
\hline & Minimum & 1.00 & 2.00 & & \\
\hline & Maximum & 4.00 & 4.00 & & \\
\hline & Std. Deviation & 0.866 & 0.707 & & \\
\hline \multicolumn{2}{|c|}{ Mean difference } & 0.222 & 0.556 & & \\
\hline \multicolumn{2}{|c|}{ Mann Whitney U test } & $\begin{array}{l}U=35.500 \\
P=0.666\end{array}$ & $\begin{array}{l}\mathrm{U}=23.000 \\
\mathrm{P}=0.136\end{array}$ & & \\
\hline
\end{tabular}

The average score in phonology in the experimental group at pre-test was 2.889 with median at 3.000 , and increased to 3.556 at post-test and this improvement was significant (Wilcoxon Signed Ranks test: $\mathrm{P}=0.043)$. In the control group, at pre-test, the average score was 2.667 and increased to 3.000 at post-test though this was not significant (Wilcoxon Signed Ranks test: $\mathrm{P}=0.180$ ) therefore implying that the change in the experimental group was more obvious than in the control group; the null hypothesis is then rejected. Comparing between the experimental and the control group, though there was an increase in the difference in favor of the experimental group, this difference was not significant (Mann Whitney U test: P>0.05).

Research hypothesis two: differentiated instruction has no significant effect on the performance of children with problems acquiring vocabulary skills

Table: Comparing vocabulary scores within group from pre-test to post-test and between experimental and control group.

\begin{tabular}{|c|c|c|c|c|c|}
\hline \multicolumn{2}{|c|}{ Group } & Vocabulary & Vocabulary & Mean difference & Wilcoxon Signed \\
\hline \multirow[t]{6}{*}{ Experimental } & $\mathrm{N}$ & 9 & 9 & \multirow{6}{*}{0.888} & \multirow{6}{*}{$\begin{aligned} Z & =-2.699 \\
P & =0.007\end{aligned}$} \\
\hline & Mean & 2.556 & 3.444 & & \\
\hline & Median & 3.000 & 3.000 & & \\
\hline & Minimum & 2.00 & 3.00 & & \\
\hline & Maximum & 3.00 & 4.00 & & \\
\hline & Std. Deviation & 0.527 & 0.527 & & \\
\hline \multirow[t]{6}{*}{ Control } & $\mathrm{N}$ & 9 & 9 & \multirow{6}{*}{0.889} & \multirow{6}{*}{$\begin{aligned} Z & =-2.333 \\
P & =0.020\end{aligned}$} \\
\hline & Mean & 1.667 & 2.556 & & \\
\hline & Median & 2.000 & 2.000 & & \\
\hline & Minimum & 1.00 & 2.00 & & \\
\hline & Maximum & 3.00 & 4.00 & & \\
\hline & Std. Deviation & 0.707 & 0.726 & & \\
\hline \multicolumn{2}{|c|}{ Mean difference } & 0.889 & 0.888 & & \\
\hline \multicolumn{2}{|c|}{ Mann Whitney U test } & $\begin{array}{c}\mathrm{U}=14.500 \\
\mathrm{P}=0.019\end{array}$ & $\begin{array}{c}\mathrm{U}=14.500 \\
\mathrm{P}=0.019\end{array}$ & & \\
\hline
\end{tabular}


The average score in vocabulary in the experimental group at pre-test was 2.556 with median at 3.000, and increased to 3.444 at post-test and this improvement was significant (Wilcoxon Signed Ranks test: $\mathrm{P}=0.007)$. In the control group, at pre-test, the average score was 1.667 and increased to 2.556 at post-test and this was significant (Wilcoxon Signed Ranks test: $\mathrm{P}=0.020$ ), therefore implying that the change in the experimental group was more obvious than in the control group; the null hypothesis is then rejected. Comparing between the experimental and the control group, there was an increase in the difference in favor of the experimental group, and this difference was significant (Mann Whitney $U$ test: $\mathrm{P}=0.019)$.

\subsection{Role of Oral Language in Developing Reading Comprehension and Recommendations of the Study}

Exposure to extended discourse at home and in preschool or kindergarten years has been identified as a key predictor of later literacy success. Tabors et al. (2001) devised an extended discourse measure made up of engaging in pretend talk during toy-play, discussing information that went beyond that present in text or pictures during book reading, and participation in narratives and explanations during dinner table conversations. This measure (using data collected at age 3 ) was a good predictor of oral language and emergent literacy skills in kindergarten. Similarly, extended discourse in children's preschool classrooms (age 4), defined as frequency of engagement in cognitively challenging talk during group activities such as book reading and morning circle (news) time, also predicted kindergarten performance. Specific recommendations for using dialogue to teach oral language, including the following:

* Structure the discussion to complement the text, the instructional purpose, and the readers' ability and grade level.

* Modeling, teachers who model how they handle the reading challenges they meet by 'thinking aloud' can help children understand what skilled readers do as they are reading, and thus provide explicit guidance to children on how to do the same.

- Direct explanation, teachers name specific strategies and talk about when they should be employed. This can improve children's use of strategies over the modeling of the strategy on its own.

* Develop discussion questions that require children to think deeply about the text.

* Ask follow-up questions to encourage and facilitate discussion.

* Verifying and clarifying children's understandings, the teacher re-voices a child's comment (or asks another child to do so), in some cases reformulating meaning, and asks the child if that was what was intended.

* Have children lead structured small-group discussions.

* Marking, the teacher responds to a child's question or comment in a way that highlights specific aspects of the text. Turning back is a similar move in which the teacher turns the conversation back to the child by asking 'What does the author say about this?'

The lack of research support for discussion for children up to class five at the Cameroon primary school in part reflects a lack of relevant studies involving children this young. It may also arise from a difficulty in separating out the effects of dialogue or discussion from the effects of comprehension strategy usage in studies that seek to implement both. Finally, as noted earlier in relation to the study, reading comprehension up to class five may not involve higher-level thinking, as children struggle to learn and apply decoding skills. On the other hand, several studies have focused on the value of discussion as a means of developing the reading comprehension skills of older children (those beyond 8 years of age) review of dialogic approaches to teaching reading comprehension, and research synthesis on comprehension and discussion of text).

\section{SUMMARY AND CONCLUSION}

In our attempts to delineate the teacher knowledgebase needed to help English Language Learners in the English Language acquire and maintain high levels of reading skills, reading emerged as central to learning in all content areas, not just in English Language classrooms. Certain effective practices were 
discussed within the domains of understanding of linguistics and pedagogy. Per the understanding of linguistics, it was emphasized that teachers should recognize the interactions of native-language literacy with literacy skills in English. Specifically, teachers should recognize that these interactions might interfere with English Language Learners' decoding skills at the lexical and syntactical levels. Also, teachers should be able to identify differences and challenges among every day, general academic, and content specific vocabulary. The literature indicates that, whereas early oral language proficiency is highly predictive of acquisition of constrained skills such as letter- name knowledge, concepts of print, phonemic awareness and oral reading fluency in the junior classes in primary school, its effects on unconstrained skills such as vocabulary knowledge and reading comprehension is less clear. Indeed, it may not be until fourth class or later that the real effects of work on developing vocabulary knowledge (particularly academic vocabulary) and knowledge of discourse (e.g. narrative discourse) have a significant impact on reading comprehension. This may be because the texts that younger readers encounter in their early reading depend more on decoding knowledge and understanding of individual word meanings than on higher-level language skills.

Nevertheless, research evidence supports the teaching of oral language and reading comprehension from preschool onwards, so that children can bridge the gap between basic reading texts encountered in early reading instruction, and more complex texts that they encounter from third or fourth class onwards, not only in English classes, but across the curriculum. The research literature has identified a number of approaches to teaching reading comprehension that draw heavily on oral language, including discussion. For example, classroom activities emphasizing the teaching of reading comprehension strategies have been shown to have a high or moderate impact on reading comprehension. It is not clear how these strategies impact on oral language since it is generally not possible to separate out the effects of the strategy from the effects of language usage or development. This arises because most studies of reading comprehension examine the effects of strategy instruction on reading comprehension rather than on oral language as well.

Another type of reading comprehension instruction for which there is somewhat limited evidence of effectiveness is discussion-based comprehension strategies - that is, approaches to teaching reading comprehension that depend heavily on discussion among children, including structuring discussion questions that require children to think deeply, asking follow-up questions that facilitate discussion, and having children lead discussion groups. Despite limited evidence from such studies (e.g. Shanahan et al., 2008), mainly due to methodological limitations, most researchers recognise the value of using discussion-based approaches such as reciprocal teaching, collaborative reasoning, questioning the author and accountable talk to foster children's engagement in discussing texts. As with instruction in specific comprehension strategies, effective discussion approaches require modeling by the teacher, direct explanation, marking (where the teacher responds to a child's question or answer by highlighting a particular aspect of the text), and verifying and clarifying children's understandings. Research on reading development confirms that two clusters of oral language abilities phonological awareness on the one hand, and general language abilities (e.g. vocabulary knowledge, syntactic knowledge) on the other are predictive of later reading ability. When delays in language development occur, they are likely to impact negatively on one or both aspects of language, and hence on reading literacy.

\section{REFERENCES}

Armbruster, B.B., Lehr, F., \& Osborn, J. (2001). Put Reading First: The research building blocks for teaching children to read, kindergarten through grade 3. Jessup, MD: Partnership for Reading, 21-32.

Association for Supervision and Curriculum Development (Producer). (1997). Differentiation instruction: Creating multiple paths for learning. (Available from the Associat ion for Supervisio nand Curriculum Development, P.O. Box 79760, Baltimore, MD 212790760)

Bauersfeld, H. (1995). "Language Games' in the Mathematics Classroom: Their Function and Their Effects", in P. Cobb \& H. Bauersfeld (Eds.), The emergence of mathematical meaning:Interaction in classroom cultures, Hillsdale, US-NJ: Lawrence Erlbaum: 211-292.

Baumgartner, T., Lipowski, T., \& Rush, C. (2003). Increasing reading achievement of primary and middle school students through differentiated instruction. Unpublished doctoral dissertation, Saint Xavier University, Chicago, IL. (ERIC Documentation Reproduction Service No. ED 479203) 
Improving Differentiated Learning Among Primary School Teachers; Enhancing the Acquisition of Phonological and Reading Comprehension Skills. The Case of Buea Sub-Division, Cameroon

Bernard-Opitz, V. (2005) Autism Spectrum Disorders: A training manual for parents, teachers and therapists, (German:Kohlhammerpublication; English in printin Pro Ed).

Bishop, D. V. M., \& Adams, C. (1990). A prospective-study of therelationship between specific language impairment, phonological disorders and reading retardation.Journal of Child Psychology and Psychiatry and Allied Disciplines, 31(7), 1027-1050

Blau, V., Reithler, J., van Atteveldt, N., Seitz, J., Gerretsen, P., Goebel, R. \& Blomert, L. (2009). Deviant processing of letters and speech sounds as proximate cause of reading failure: a functional magnetic resonance imaging study of dyslexic children. A Jounral of Neurology, 133, 868-879.

Brooks, J. G., \& Brooks, M. G. (1993). In search of understanding: The case for constructivist classrooms.Alexandria, VA: Association for Supervision and Curriculum Development.

Caine, R., Caine, G., \&Crowell, S. (1999). Mindshifts: A Brain-Compatible Process for Professional Development and the Renewal of Education Tucson, Ariz : Zephyr Press

Caine, R., Caine, G., McClintic, C., \&Klimek, K.(2009)12 Brain/Mind LearningPrinciples in Action: Developing Executive Functions of the Human Brain.Thousands oaks, Calif : Corwin Press

Christensen, T. (1993). Individualizing reading assignments in large class language study. Journal of Hokusei Junior College, 29, (pp. 85-101). (ERIC Document Reproduction Service No. ED346082)

Collins, A., \& Brown, J. S. (1988). The computer as a tool for learning through reflection. In H. Mandl \&A. Lesgold (Eds.), Learning issues for intelligent tutoring systems (pp. 1-18). New York: Springer Verlag.

Collins, A., Brown, J. S., \& Newman, S. (1989). Cognitive apprenticeship: teaching the crafts of reading, writing, and mathematics. In L. B. Resnick (Ed.), Knowing, learning, and instruction: Essays in honor of Robert Glaser(pp. 453-494). Hillsdale, NJ: Erlbaum.

Csikszentmihalyi, M. Rathunde, K., \& Whalen, S. (1993). Talented teenagers: The roots of success and failure. New York: Cambridge University Press.

Cummins, J. (1980). The cross-lingual dimensions of language proficiency. Implications for bilingual education and the optimal age issue. TESOL Quarterly, 14, 175-187.

D'Amico, J. \& Gallaway, K. (2008). Differentiated instruction for the middle school math teacher; activities and strategies for an inclusive classroom. Hoboken, N. J.: Wiley Pub.

Davis, E. A., \& Linn, M. C. (2000). Scaffolding students'knowledge integration: Prompts for reflection in KIE. International Journal of Science Education, 22, 819-837.

Dennis, M., \& Barnes, M. (1993). Oral discourse after early-onset hydrocephalus: Linguistic ambiguity, figurative language, speech acts and script-based inferences. Journal of Pediatric Psychology, 18, 639-652.

Dinnocenti, S.T. (1998). Differentiation: Definition and description for gifted and talented students. Storrs, CT: National Research Center on the Gifted and Talented. (ERIC Document Reproduction Service No. ED424709)

Edelson, D. C., Gordin, D. N., \& Pea, R. D. (1999). Addressing the challenges of inquiry-based learning through technology and curriculum design. The Journal of the Learning Sciences, 8, $391-450$.

Edelson, D. C., Pea, R. D., \& Gomez, L. (1996). Constructivism in thecollaboratory. In B. Wilson (Ed.), Constructivist Learning Environments: Case Studies inInstructional Design,. Englewood Cliffs, NJ: Educational Technology Publications.

Ehri, L.C. (2002). Phases of acquisition in learning to read words and implications for teaching. In R. Stainthorp and P.Tomlinson (Eds.) Learning and teaching reading. London: British Journal of Educational Psychology Monograph Series II

Fabrizio, M. A. \& Moors, A. L. (2003)Evaluating Mastery: Measuring Instructional Outcomes for Children with Autism. European Journal of Behavior Analysis.

Feldman, R. S. (2003). Development across the Life Span. (3rd ed) Upper Saddle River, New Jersey.

Gamoran, A., Secada, W. G.,\& Marrett, C. B. (2000). The organizational context of teaching and learning. InHandbook of the sociology of education(pp. 37-63). Springer US. 
Gernsbacher, M. A. (1990). Fine tuning the activation of lexical representations during comprehension. In G. B. Simpson (Ed.), Comprehending word and sentence. Amsterdam: NorthHolland

Gernsbacher, M. A., \& Faust, M. E. (1991). The mechanism of suppression: A component of general comprehension skill. J. of Experimental Psychology: Learning, Memory and Cognition 17, 245262

Gilbert, T. F. (1978). Human Competence: Engineering worthy performance. New York: McGraw Hill.

Gindis, B. (2003) Remediation through Education: Sociocultural Theory and Children with Special Needs. In: Kozulin et al. (Eds.) Vygotsky`s Educational Theory in Cultural Context.( Cambridge University Press), 200-225.

Hall, T. (2002). Differentiated Instruction. Effective Classroom Practices Report. National Center on Accessing the General Curriculum, CAST, U.S. Office of Special Education Programs. [Online] http://www.cast.org/ncac/classroompractice/cpractice02.doc [15 May 2005].

Hogan, K., \& Pressley, M. (1997). Scaffolding scientific competencies within classroom communities of inquiry. In K. Hogan \& M. Pressley (Eds.), Scaffolding student learning: Instructional approachesand issues (pp. 74-107). Cambridge, MA: Brookline.

Hollas, B. (2005). Differentiating Instruction in a Whole-Group Setting: Taking the Easy First Steps into Differentiation. Peterborough, NH: Crystal Springs Books.

Juel, C. (1988). "Learning to Read and Write: A Longitudinal Study of Fifty-Four Children from First Through Fourth Grade." Journal of Educational Psychology, 80, 437-447.

King-Friedrichs, J. (2001). Brain friendly techniques for improving memory. Educational Leadership, 59(3), 76-79.

Kitao, K. (1994). Individualizing English instruction using computers. Doshisha Studies in English, 62, (pp. 167-190). (ERIC Document Reproduction Service No. ED377675)

Koedinger, K. R., \& Anderson, J. R. (1993). Reifying implicit planning in geometry: Guidelines for model-based intelligent tutoring system design. In S. P. Lajoie \& S. J. Derry (Eds.), Computers ascognitive tools (pp. 15-45). Hillsdale, NJ: Lawrence Erlbaum Associates, Inc.

Kolodner, J., Owensby, J., \& Guzdial, M. (2004). Case-based learning aids. In D. H. Jonassen (Ed.), Handbook of research on educational communications and technology: A project of the Association for Educational Communications and Technology(2nd ed., pp. 829-861). New York: L. Erlbaum.

Laing, E., Hulme, C., Grant, J., \& Karmiloff-Smith, A. (2001). Learning to read in Williams syndrome: Looking beneath the surface of atypical reading development. Journal of Child Psychology and Psychiatry, 42, 729-739.

Larkin, L.K., Sackor, S.M., \& Zigmond, N.(2002). Teaching reading to poor readers in the intermediate grades: A comparisonof text difficulty. Journal of Educational Psychology, 94(3), 474-485.

Leach, D., Coyle, C.A. \& Cole, P. G. (2003) Fluency in the Classroom. In:Waugh, R. F. On the Forefront of Educational Psychology, New York:Nova Science Publishers, Inc.

Lepper, M. R., Woolverton, M., Mumme, D. L., \& Gurtner, J. (1993). Motivational techniques of expert human tutors: Lessons for the design of computer-based tutors. In S. P. Lajoie \& S. J. Derry (Eds.), Computers as cognitive tools (pp. 75-105). Hillsdale, NJ: Lawrence Erlbaum Associates, Inc.

Lindsley, O. R. (1972). From Skinner to Precision Teaching. In J. B. Jordan \& L. S. Robbins(Eds.), Let's try doing something else kind of thing (pp. 1-12). Arlington, VA: Council on ExceptionalChildren.

Long, D. L., Seely, M. R., \& Oppy, B. J. (1999). The strategic nature of less skilled readers' suppression problems. Discourse Processes, 27, 281-302.

McGill-Franzen, A., Zmach, C., Solic, K., \& Zeig, J. L. (2006). The confluence of two policy mandates: Core reading programs and third-grade retention in Florida. Elementary School Journal, 107(1), 67-91.

Mitchell, L., \& Hobson, B. (2005). One Size Does Not Fit All: Differentiation in the Elementary Grades. Paper presented at the Beaverton School District Summer Institute, Beaverton, OR. 
Molenda, M. J., Pershing, J. A. and Reigeluth, C. M. (1996), "Designing Instructional Systems”. In R. L. Craig (Ed).TheASTD Training and Development Handbook, (4th ed pp266-293). New York: McGraw Hill.

Moody, S. W., Vaughn, S., \& Schumm, J. S. (1997). Instructional grouping for reading: Teachers' views. Remedial and Special Education, 18(6), 347-356.

Nation, K. \& Snowling. M.J. (1997) Assessing reading difficulties: the validity and utility of current measures of reading skill. British Journal of Educational Psychology, 67, 359-370.

Quintana, C., Eng, J., Carra, A., Wu, H.-K., \& Soloway, E. (1999). Symphony: A case study in extending learner-centered design through process space analysis. In M. G. Williams, M. W. Altom, K. Ehrlich, \& W. Newman (Eds.), Proceedings of CHI 99 Conference on Human Factors in ComputingSystems (pp. 473-480). Reading, MA: Addison-Wesley.

Ramiro, M. (2013). New methods and strategies for teaching Mathematics and reading have been implemented in nursery and primary schools in the Southwest Region. CameroonPostline.com

Reiser, B. J., Tabak, I., Sandoval, W. A., Smith, B. K., Steinmuller, F., \& Leone, A. J. (2001). BGuILE: Strategic and conceptual scaffolds for scientific inquiry in biology classrooms. In S. M. Carver \& D. Klahr (Eds.), Cognition and instruction: Twenty-five years of progress (pp. 263305). Mahwah, NJ: Lawrence Erlbaum Associates, Inc.

Schumm, J. S., Moody, S. W. \& Vaughn. S. R. (2000). Grouping for reading instruction: Does one size fit all? Journal of Learning Disabilities, 33 (5), pp. 477-488.

Servilio, K. (2009). You get to choose! Motivating students to read through differentiated instruction. Teaching Exceptional Children Plus, 5(5), 2-11.

Sharma, M., Purdy, S.C, Newall, P., Wheldall, K., Beaman, R. \& Dillon, H. (2006). Electrophysiological and behavioral evidence of auditory processing deficits in children with reading disorder. Clinical Neurophysiology, 117, 1130-1144.

Sigman, M., \& Ungerer, J. (1981). Sensorimotor skill and language comprehension in autistic children. Journal of abnormal Child Psychology, 9, 149-165.

Stanovich, K.E. (1986). "Matthew Effects in Reading: Some Consequences of Individual Differences in the Acquisition of Literacy." Reading Research Quarterly, 21, 360-406.

Subban, P. (2006). Differentiated instruction: A research basis. International Education Journal, 7(7), 935-947. ISSN 1443-1475 @ 2006 Shannon Research Press

Sullivan, M. (1993). A meta-analysis of experimental research studies based on the Dunn and Dunn learning styles model and itsrelationship to academic achievement and performance.Unpublished doctoral dissertation, St. John's University,Jamaica, NY.

Tchombe, T. M. S. (2011) Theories of learning. In Nsamenang, A. B. \& Tchombe, T. M. S. (Eds) Handbook Of African Educational Theories And Practices: A Generative Teacher Education Curriculum. Human Development Resource Centre. Bamenda. pp 175 - 193

Temple, C.M. \& Carney, R. (1996) Reading skills in children with Turner' s Syndrome: An analysis of hyperlexia. Cortex, 32, 335-345

Thames, D.G., \& Reeves-Kazelskis, C. (1992). Effects of individualized, integrated language arts instruction on the attitudes of poor readers. Knoxville, TN: Mid-South Educational Research Association. (ERIC Document Reproduction Service No. ED353570)

Tieso, C. (2005). The effects of grouping practices and curricular adjustments on achievement. Journal for the Education of the Gifted, 29(1), 60-89.

Tomlinson, C. A. (1999). The differentiated classroom: Responding to the needs of all learners. Alexandria, Virginia: Association for Supervision and Curriculum Development.

Tomlinson, C. A. (2001). How to differentiate instruction in mixed-ability classrooms. Alexandria, VA. Association for Supervision and Curriculum Development

Tomlinson, C. A. (2003). Fulfilling the Promise of the Differentiated Classroom: Strategies and Tools for Responsive Teaching. Alexandria, VA: ASCD.

Tomlinson, C. A., and Kalbfleisch, M. L. (1998). Teach me, teach my brain: A call for differentiated classrooms. Educational Leadership, 56(3), 52-55 
Tomlinson, C. A., Brighton, C., Hertberg, H., Callahan, C. M., Moon, T., \& Brimijoin K., Conover, L.A. \& Reynolds, T. (2003). Differentiating instruction in response to student readiness, interest, and learning profile in academically diverse classrooms: A review of the literature. Journal for the Education of the Gifted, 27 (2/3), 119-45.

Tomlinson, C. A., Brighton, C., Hertberg, H., Callahan, C. M., Moon, T., \& Brimijoin K., Conover, L.A. \& Reynolds, T. (2003). Differentiating instruction in response to student readiness, interest, and learning profile in academically diverse classrooms: A review of the literature. Journal for the Education of the Gifted, 27 (2/3), 119-45.

Tuttle, J. (2000). Differentiated Classrooms (Report). Woodbury: Cedar Mountain Academy.

Vygotsky, L. (1993). The collected works of L.S.Vygotsky. Vol.2: The fundamentals of defectology (abnormal psychology and learning disabilities) (R.W.Rieber \& A.S. Carton, Eds.). NY: Plenum Press.

Vygotsky, L.S. (1978). Mind and Society: The development of higher mental processes. Cambridge, MA: Harvard University Press

Wendling, B.J., \& Mather, N., (2009). Essentials of Evidence-Based Academic Interventions. New Jersey: John Wiley \& Sons, Inc.

Westwood, P. (2008). What teachers need to know about Learning difficulties. Camberwell: Australian Council for Educational Research (ACER).

Westwood, P., (2001). Reading and learning difficulties: Approaches to teaching and assessment. Camberwell: Australian Council for Educational Research (ACER).

Williams, J.H.G., Whiten, A., \& Singh, T. (2004). A Systematic Review of Action Imitation in Autistic Spectrum Disorder. Journal of Autism and Developmental Disorders, 34 (3),285-299.

Wood, D., Bruner, J., \&Ross, G. (1976) The role of tutoring in problem solving. Journal of ChildPsychol.Psychiat.,Vol. 17, 1976, pp. 89 to 100. Pergamon Pres

Wood, S., Burke, L., Kunzelmann, H., \& Koenig, C. (1978). Functional criteria in basic math skill proficiency. Journal of Special Education Technology, 2, 29-36.

Yuen, K.M. \& Hau, K.T. (2006). Constructivist teaching and teacher-centred teaching: a comparison of studentse learning in a university course. Innovations in Education and Teaching International, Vol.43 No.3, pp. 279-290. 